\title{
Impact of crack length into pipe conveying fluid utilizing fast fourier transform computer algorithm
}

\author{
Radhwan Hussein Abdulzhraa Al-Sagheer ${ }^{1}$, K. I. Mohammed ${ }^{2}$, Alaa Abdul Hussein Mezher ${ }^{3}$, \\ Karrar Abdullah Mohammed Habeeban ${ }^{4}$ \\ ${ }^{1,4}$ Department of Computer Science, Faculty of Education for Girls, University of Kufa, Iraq \\ ${ }^{2}$ Ministry of Oil in Iraq, Midland Refineries Company, Najaf Refinery, Iraq \\ ${ }^{3}$ Department of Computer Science, Faculty of Computer Science and Mathematics, University of Kufa, Iraq
}

\begin{tabular}{l}
\hline \hline Article Info \\
\hline Article history: \\
Received Apr 23, 2018 \\
Revised Dec 25, 2018 \\
Accepted Jan 10, 2019 \\
\hline
\end{tabular}

\section{Keywords:}

Fast fourier transform

Oil refineries

Pipe cracks

Ultrasonic flow meter

\begin{abstract}
One of the most prominent problems experienced by the oil facilities is leakage of oil from the pipes. This problem caused $55 \%$ of oil refineries to be shut off. Oil leakage is a common problem that often results in oil waste, damage, and hazard to public health. Therefore, it is necessary to use Modern technologies to reduce this phenomenon and avoid them in advance. Pipes that convey fluids have many uses in various industries and living facilities. Risk increases when the fluid inside the pipe is flammable. In this work, main case that cause damage to the pipe, longitudinal crack is investigate.This work presents a new experimental model based on computer applications with a Fast Fourier transform (FFT) algorithm for testing the effect of longitudinal crack length by frequency and ultrasonic measurements to measure fluid velocity. The method is used for plastic pipe with $2 \mathrm{~cm}$ internal diameter, $3 \mathrm{~cm}$ external diameter, and $1 \mathrm{~m}$ length. The modulus of elasticity of the material is $800 \mathrm{~N} / \mathrm{mm} 2$ according to the ISO 178 test method. The pipe conveys oil with simply supported ends. The results show that FFT model shows better features compared with other ways that depends on visual inspection or localized measurements which gave an external perception of pipeline damage. FFT model offers a reliable and cheap style for ensuring pipeline integrity and warning the risks before its occurrence. From the observations made the fundamental natural frequency (FNF) decreases by increasing of crack length in the pipe that conveys fluid.
\end{abstract}

Copyright (C) 2019 Institute of Advanced Engineering and Science. All rights reserved.

\section{Corresponding Author:}

Radhwan Hussein Abdulzhraa Al-Sagheer,

Department of Computer Science, Faculty of Education for Girls,

University of Kufa,

Najaf, Iraq.

Email: radhwan.hu@uokufa.edu.iq

\section{INTRODUCTION}

Pipelines are very important for uses in life; it is widely used to include houses, laboratories, oil refineries, and other important facilities. The pipe is classified two types thin and thick walled pipe. If the ratio of internal pipe diameter to pipe thickness bigger than twenty, the pipe is thin. Else, the pipe is thick when the ratio less than twenty [1]. Fluid flow into pipe causes stress in axial direction called longitudinal stress that results in cracks toward the cross-section of the pipe, stress in circumferential of pipe is called hoop stress cause cracks in the longitudinal direction, also it is a frequent occurrence, and the radial stress toward the pipe in central axis (the diameter direction) as illustrated in Figure 1. 
Fluid velocity inside the pipe has an effect on flow specification. Hence, laminar and turbulent are the fluid flow types according to the Reynolds number "the ratio of inertia force to viscosity force" equation $1[2]$.

$$
\mathrm{Rn}=\frac{\rho \mathrm{VD}}{\mu}
$$

where:

$\mathrm{Rn}=$ dimensionless number

$\rho=$ liquid density $\left(\frac{\mathrm{kg}}{\mathrm{m}^{3}}\right)$

$\mathrm{V}=$ liquid velocity $\left(\frac{\mathrm{m}}{\mathrm{sec}}\right)$

$\mathrm{D}=$ diameter of pipe $(\mathrm{m})$

$\mu=$ dynamic viscosity $\left(\frac{\mathrm{N} . \mathrm{S}}{\mathrm{m}^{2}}\right)$

In the laminar flow the streamlines are smooth and Renold number less than 2000, in turbulent flow the velocity fluctuations and Rn greater than 4000 as illustrated in Figure 2.

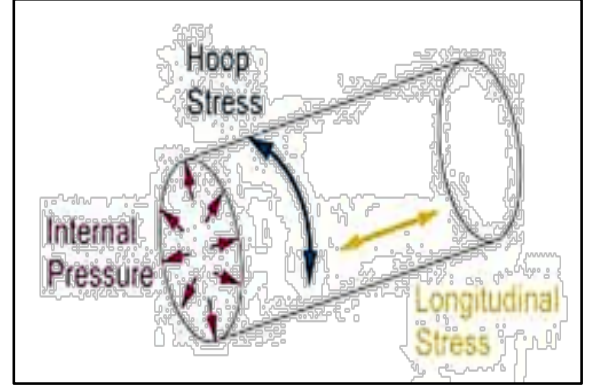

Figure 1. Stress effects in pipe

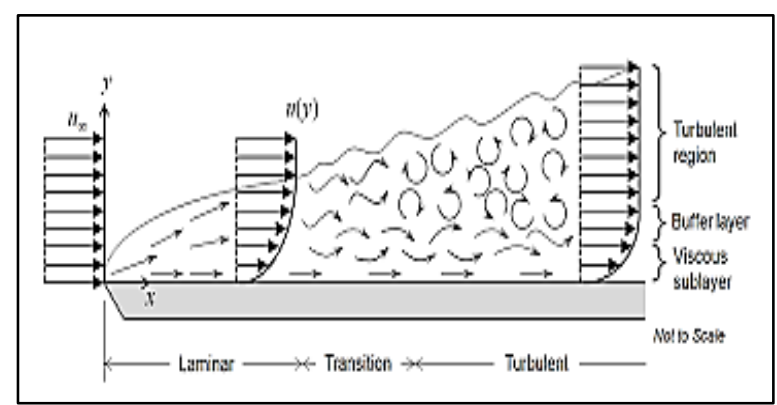

Figure 2. Fluid flow specification

The laminar flow velocity is chosen. On the other side, the tube is exposed to Fatigue Failure (FF) during fluid flow in the pipe [3]. FF is progressive cracking of its brittle metal due to repeated or periodic pressure. This failure may cause problems related to safety, infrastructure, and other physical and moral problems. FF depends on the stress strength applied in a repeated period. FF can be connected to new crack generation and their rapid growth. FF is readily accelerated by corrosion on surfaces of metal. It has been observed that $90 \%$ of failure for mechanical parts due to fatigue. It is more memorable in pipes, pumps, and engines. FF beginning from holes, internal cracks or cavities. Then, the cracks reach the metal surface. The crack detection process is important, as an example of that significance the explosion in heat exchange of Tesoro's Anacortes refinery Washington on April 2010 [4]. The explosive heat exchanger used to transfer temperature between crude oil low and naphtha.

A fouling scale accumulates inside of the tube of the heat exchanger. The increase of temperature led to accumulating methylene into the heat exchanger. Hence, led to large internal crack because of the increase in the internal stress. The fire was caused by the release of naphtha and hydrogen vapor into the air.

Seek to reduce as these risks by developing new computer applications that can inform of danger before it occurs to avoid losses as much as possible. There are factors that affect the formation and growth of the crack in metal and these factors may be from external influences as thermal effects, Corrosion, and erosion effects. Pipes transmitting the fluid are exposed to a range of effects as pressure effects, Carioles force effects, and centrifugal force effects.

\section{RELATED WORKS}

Many researchers were making many studies on the pipes in the oil industry that showed pipe problems and the solutions for it, investigating the effect of different end conditions on the natural frequency of pipe conveying fluid with different flow velocities. The analytical solution and experiment have good agreement [5]. Cracks effect in pipes conveying fluid with a certain flow velocity on frequencies using different crack locations and depths are investigated. The increase of crack depth decreases the frequency of the fluid transmitted through the cracked pipe [6]. 
A modem analytical sample for inner raceway of bearing defect is presented. The results of the experimental work explain that the signature analysis of the stator current can be used to distinguish the fault in bearing based on the simulation of the spectral test of a signal using FFT. Moreover, the experimental results benefitted from the suggested sample [7]. Studying the analytical forming of the cracks effects in constructional plates and panels within the systems of aerospace such as structures of tail-plane, wing, and airplane fuselage, this research based on producing a so-called reduced order analytical model of the action for the plate panel withcrack and subjected to a force to vibrate the plate [8].

Studying the analysis of pipes conveying fluid flow numerically to determine the vibration effects into pipe. Also, implementing the above developed model to simply supported pipe [9]. Analytical solution to critical velocity of buckling pipe with simply supported and various boundary conditions, this paper included conclude the general equation of motion of vibrated pipe conveying fluid flow. Also, investigation the effect by using the experimental method [10]. Studying the effect of increasing the angle of the crack from zero to 90 degrees for the same point and the same length of the crack. Where the vertical longitudinal section was found to be more effective at vibration than the horizontal incision [11].

Experimental investigation and analysis of pipe conveying fluid induced vibration by search the turbulence effect of the gas flow in the system through the path of sub cooling of flow trial or flight static fire test [12]. Studying the effect of the pipe metal on the performance of the tube structure. A clamped Pinned Pipeline is studied; taking into consideration the dynamic effects of the stabilization system [13]. Using a sensor Force-sensing resistor to study the change in diameter of the tube and detect the leakage of pipes. Study the effect of different pipe diameter on water flow pressure in pipes and temperature changes around the pipe [14].

\section{RESEARCH OBJECTIVE}

Oil transport pipes are widely installed in different places of the world and from the past experiences, there is great potential for the occurrence of ecological disaster and losses of human resources and economic in oil institutions. These possibilities increase with the pipe aging (corrosion, leakage, high pressure for fluid in pipelines). Thus, Traditional maintenance of pipeline that depends on visual inspection or current measurements does not give any prediction of losses before they happen.

Using modern techniques to reduce and avoid these risks in advance, by using Computer software applications and FFT is the aim of this work. Work has been acceptable proved under Specific cases and hope to carry out this work in oil refineries to be more mature.

\section{FAST FOURIER TRANSFORM}

Technological progress presents many applications have appeared as digital Signal processing applications, modern computers, communication systems etc. It's important to take care of things like realtime, quick execution, computation time and error avoidance. FFT is an algorithm or tool capable of achieving these goals [15]. Increases the efficiency and quality of the system. Getting frequency representation from time representation as illustrated in Figure 3. This is a new idea and it opens a modern world of great ideas. FFT algorithm is defined as shown in (2).

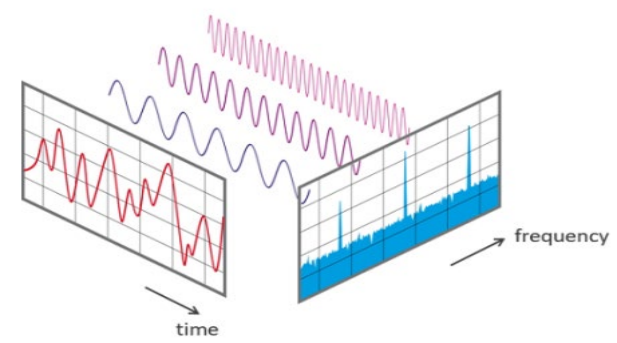

Figure 3. Signal representation in time and frequency domain

$$
\begin{gathered}
X(k)=\sum_{n\lrcorner 0}^{N-1} x(n) W_{N}^{k n}, \quad 0 \leq k \leq N-1 \\
W_{N}=e^{-j 2 \pi / N}
\end{gathered}
$$


The divide-conquer and recursion methods are the basic application of this algorithm to reduce the computations by solving the complex problem by partition it to simple problems with the following form [15]

$\left(\sum\right.$ Cost (simple problems) + Cost (partitioning) $)<$ Cost (complex problem)

\section{MATERIALS AND METHODS}

Proposed longitudinal crack in the tube, a PVC tube with $900 \mathrm{~kg} / \mathrm{m}^{3}$ martial density, $800 \mathrm{~N} / \mathrm{mm}^{2}$ modulus of elasticity, and $40 \mathrm{~N} / \mathrm{mm}^{2}$ ultimate strength is used. The internal and external diameters of the pipe are 2 and $3 \mathrm{~cm}$, respectively, and its length is $1 \mathrm{~m}$. The methodology of this work is concentrated on the design and implementation of the model that senses cracks before and after they occur in pipes. Modeling based on the calculation of the difference in frequencies of tubes that transport the fluid. Figure 4 shows the methodology of successful design architecture for work and the system requirements shall be discussed in detail. FFT is an algorithm or tool increases the efficiency and quality of work [15]. It enables to switch from the time/ frequency domain. The sample rate is needed to determine the frequency domain from the time domain. This is done by building a program has the algorithm specification shown in algorithm 1 to achieve the desired goal.

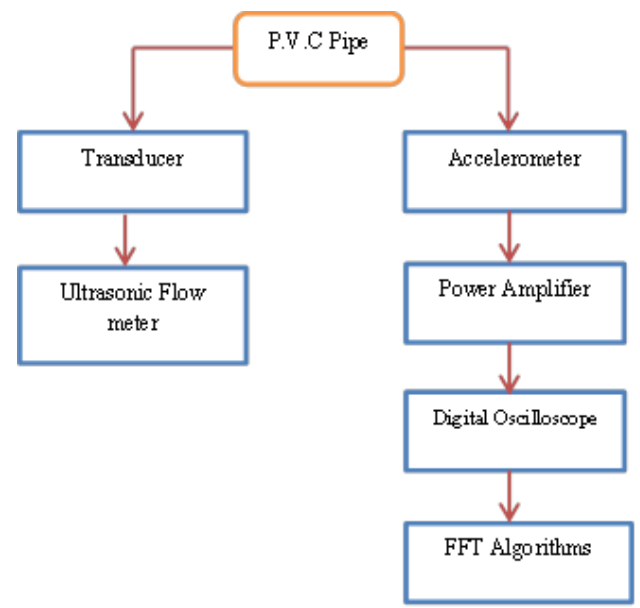

Figure 4. Model implementation

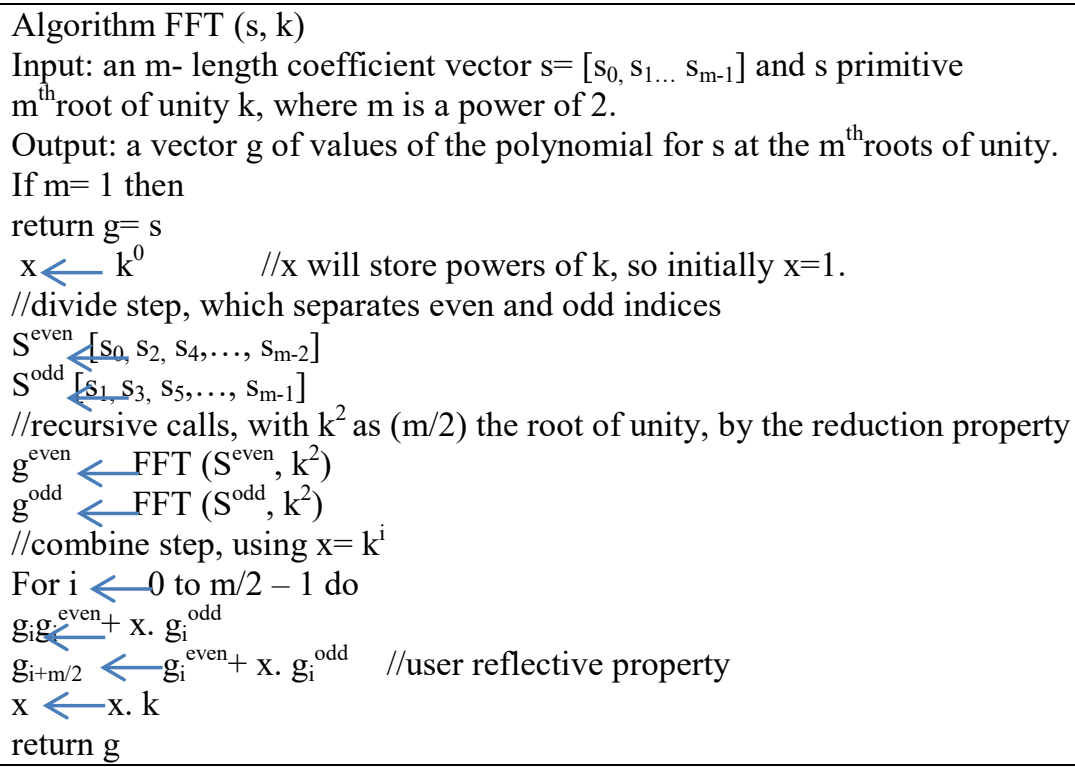

Algorithm 1. Recursive FFT algorithm 
FFT collects oscilloscope's voltage in time to convert them into volts in frequency. This transition from the time domain to the frequency domain is the basic work.

\subsection{Action steps}

The following points are summarize of the work steps:

a. Pass the fluid in the tube.

b. Regulate the flow rate of the fluid at a certain quantity.

c. Calculate the voltages that generated in the tube.

d. Amplify the voltage.

e. Collect the voltages and display them.

f. Convert voltages from the time domain to frequency domain.

g. Calculate the natural tube frequency.

h. Sense the defects of the tubes by calculating their frequencies and comparing them with natural tube frequency.

\section{RESULTS AND DISCUSSION}

UFM and Oscilloscope present a regular flow rate of oil and a file that consists of voltage in the time domain. FFT generated by utilizing Matlab computer programming language, convert these voltages to frequency domain spectrum to determine the FNF as illustrated in Figure 5. PVC pipe is tested to investigate the effect of the crack length on the FNF with taking into consideration the stages and constants shown in the Table 1. Figures 6,7 , and 8 shows that the crack position from the pipe length is $0.25,0.375$, and 0.5 , respectively.
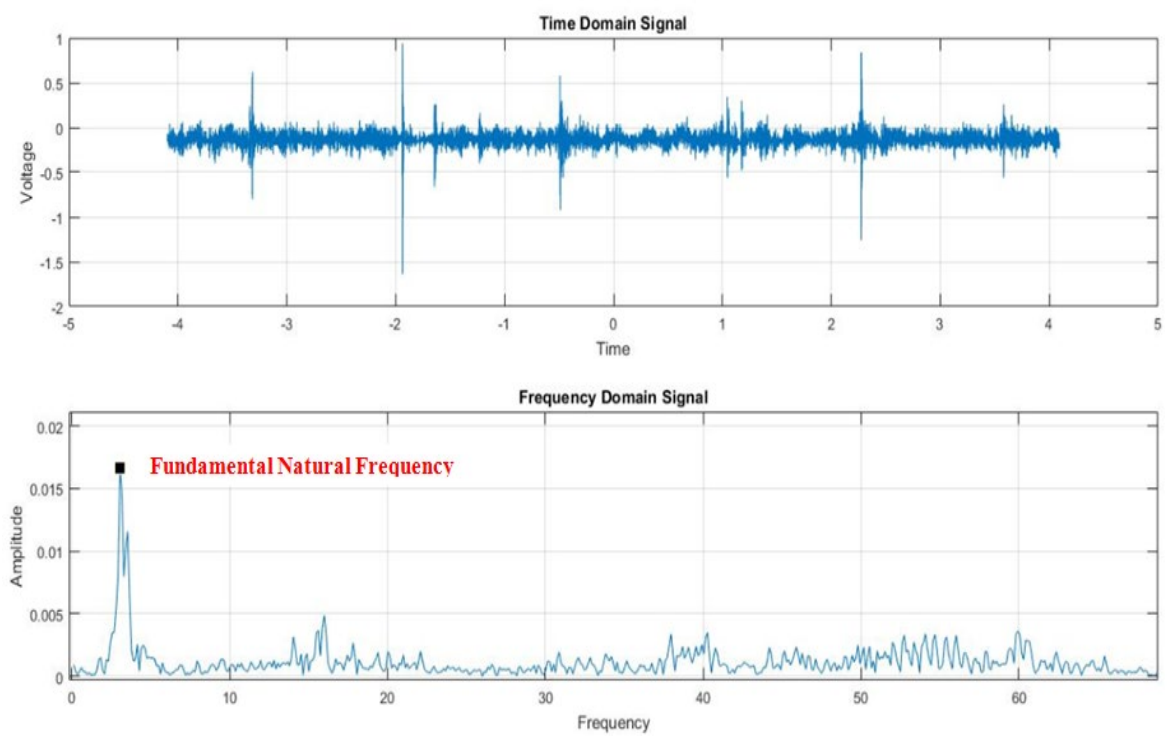

Figure 5. Signals in/out FFT

Table 1. Experimental working environment

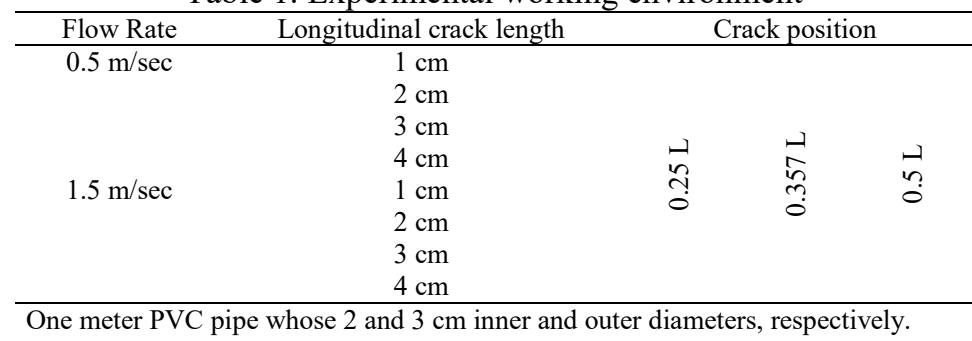

The crack depth from the outer PVC pipe surface is $3.5 \mathrm{~mm}$. 


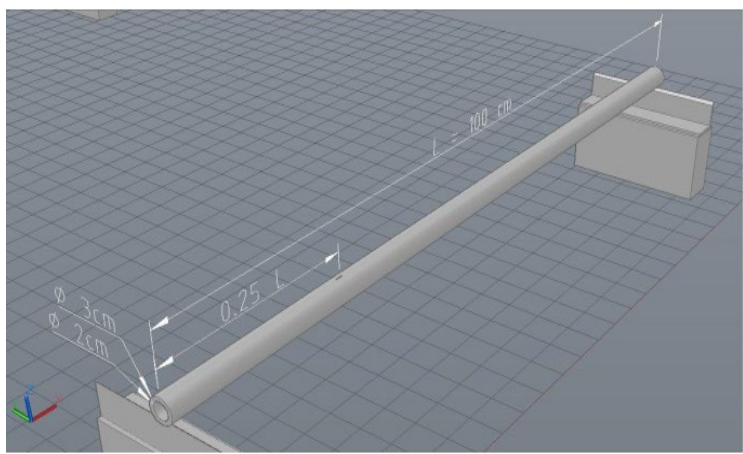

Figure 6. Crack position $0.25 \mathrm{~cm}$

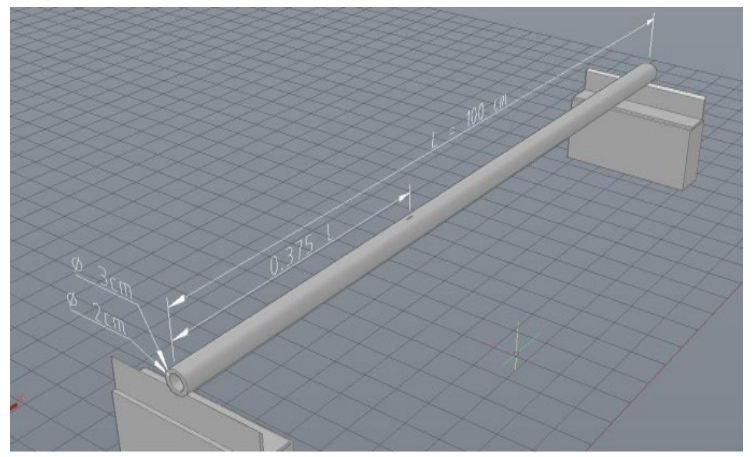

Figure 7. Crack position $0.375 \mathrm{~L} \mathrm{~cm}$

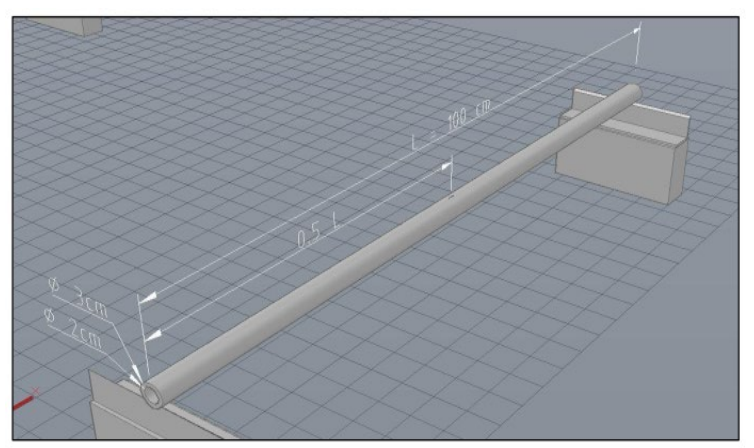

Figure 8. Crack position $0.5 \mathrm{~L} \mathrm{~cm}$

Table 2 show that the frequency decreases due to the increase in crack length. For example, the FNF of the pipe transmitting fluid in $0.5 \mathrm{~m} / \mathrm{sec}$ fluid velocity is $152.0247 \mathrm{rad} / \mathrm{sec}$ for the pipe without crack and 147.2980 for the pipe with $1 \mathrm{~cm}$ crack length in the middle, that is, the reduction percentage is $3.289 \%$. FNF with $4 \mathrm{~cm}$ crack length in the same case is $140.7373 \mathrm{rad} / \mathrm{sec}$, the reduction percentage is $7.4 \%$. Figure 9 shows that the reduction of the FNF is slightly changed due to the increase in crack length.

Table 3 shows that the frequency decreases due to the increase in crack length. For example, the FNF of the pipe transmitting fluid in $0.5 \mathrm{~m} / \mathrm{sec}$ fluid velocity is $133.3562 \mathrm{rad} / \mathrm{sec}$ for the pipe without crack and $128.3838 \mathrm{rad} / \mathrm{sec}$ for the pipe with $1 \mathrm{~cm}$ crack length in the middle, the reduction percentage is $3.73 \%$. FNF with the $4 \mathrm{~cm}$ crack length in the same case is $118.1120 \mathrm{rad} / \mathrm{sec}$, the reduction percentage is $11.4 \%$. Figure 10 shows that the reduction of the FNF is slightly changed due to the increase in crack length.

Table 2. FNF in the pipe with flow rate is $0.5 \mathrm{~m} / \mathrm{sec}$

\begin{tabular}{|c|c|c|}
\hline \multicolumn{3}{|c|}{ Without crack pipe } \\
\hline Sequence & $\begin{array}{c}\text { Crack } \\
\text { length }(\mathrm{cm})\end{array}$ & $\begin{array}{l}\text { fundamental natural } \\
\text { frequency }(\mathrm{rad} / \mathrm{sec})\end{array}$ \\
\hline 1 & 0 & 152.0247 \\
\hline \multicolumn{3}{|c|}{ Cracked pipe (crack position $0.25 \mathrm{~L}$ ) } \\
\hline 2 & 1 & 150.3670 \\
\hline 3 & 2 & 148.0297 \\
\hline 4 & 3 & 146.2223 \\
\hline 5 & 4 & 143.6362 \\
\hline \multicolumn{3}{|c|}{ Cracked pipe (crack position $0.375 \mathrm{~L}$ ) } \\
\hline 6 & 1 & 149.0028 \\
\hline 7 & 2 & 147.2872 \\
\hline 8 & 3 & 144.9282 \\
\hline 9 & 4 & 142.5843 \\
\hline \multicolumn{3}{|c|}{ Cracked pipe (crack position $0.5 \mathrm{~L}$ ) } \\
\hline 10 & 1 & 147.2980 \\
\hline 11 & 2 & 145.0001 \\
\hline 12 & 3 & 142.9873 \\
\hline 13 & 4 & 140.7373 \\
\hline
\end{tabular}

Table 3. FNF in the pipe with flow rate is $1.5 \mathrm{~m} / \mathrm{sec}$

\begin{tabular}{|c|c|c|}
\hline \multicolumn{3}{|c|}{ Without crack pipe } \\
\hline Sequence & $\begin{array}{c}\text { Crack } \\
\text { length }(\mathrm{cm})\end{array}$ & $\begin{array}{l}\text { Fundamental natural } \\
\text { frequency }(\mathrm{rad} / \mathrm{sec})\end{array}$ \\
\hline 1 & 0 & 133.3562 \\
\hline \multicolumn{3}{|c|}{ Cracked pipe (crack position $0.25 \mathrm{~L}$ ) } \\
\hline 2 & 1 & 131.2877 \\
\hline 3 & 2 & 128.9910 \\
\hline 4 & 3 & 126.1099 \\
\hline 5 & 4 & 123.6276 \\
\hline \multicolumn{3}{|c|}{ Cracked pipe (crack position $0.375 \mathrm{~L}$ ) } \\
\hline 6 & 1 & 130.2983 \\
\hline 7 & 2 & 127.2002 \\
\hline 8 & 3 & 123.2873 \\
\hline 9 & 4 & 120.0001 \\
\hline \multicolumn{3}{|c|}{ Cracked pipe (crack position $0.5 \mathrm{~L}$ ) } \\
\hline 10 & 1 & 128.3838 \\
\hline 11 & 2 & 125.1092 \\
\hline 12 & 3 & 121.9100 \\
\hline 13 & 4 & 118.1120 \\
\hline
\end{tabular}




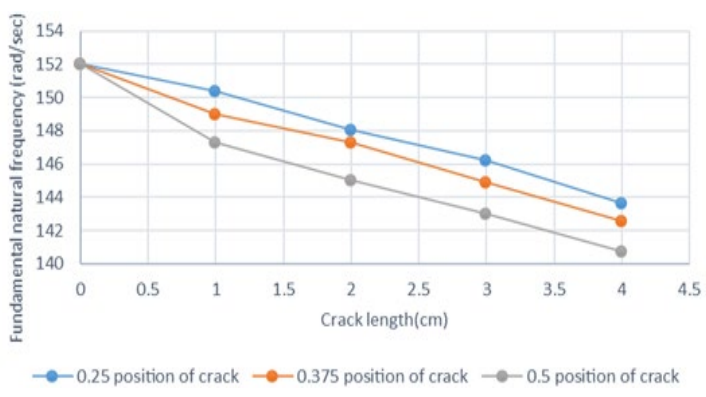

Figure 9. The effect of crack length in FNF

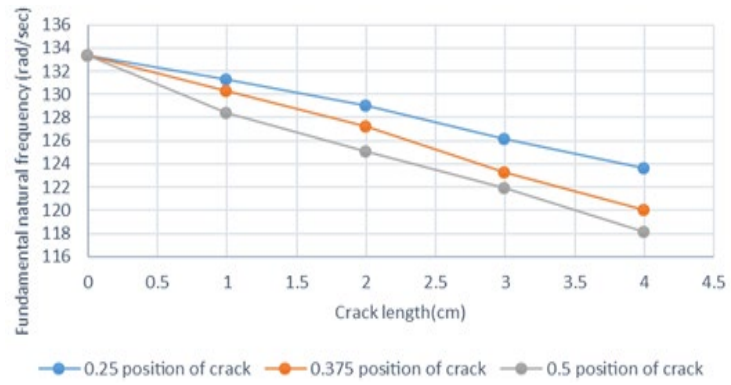

Figure 10. The effect of crack length in FNF

The results of our experimental work from Table 2 and 3 proved that the frequency of pipe will be less than FNF by increasing the length of the crack and will be same FNF when there is no crack

\section{CONCLUSION}

The cracks cannot stop, but reduce their risks in pipelines carrying fluid are possible. In this paper, a new detection model based on computer technique and electrical equipment has been introduced to accomplish the crack detection process and to decrease the searching process. The proposed model included three major parts: regulating a flow rate of oil, calculating the natural frequency of the proper pipe without and with the crack, and frequencies Comparison using matlab program.

FFT and collected property accelerometer dataset are utilized in order to examine the proposed model. The experimental results showed that the proposed detection model outperformed the traditional detection methods in terms of accuracy, sensitivity and speed in detecting cracks at or before they occur. Future research it is worth considering additional pipe features as other types of rift and different temperature to get more accurate results.

\section{REFERENCES}

[1] A. P. Moser and S. L. Folkman, "Buried pipe design,” New York, McGraw-Hill, 2001.

[2] H. Schlichting and K. Gersten, "Boundary-layer theory," Springer, 2016.

[3] P. K. Selvam, et al., "Large eddy simulation on thermal mixing of fluids in a T-junction with conjugate heat transfer," Nuclear Engineering and Design, vol. 284, pp. 238-246, 2015.

[4] D. Zaini, et al., "Inherently Safe Heat Exchanger Network Design by Consequence Based Analysis," Procedia engineering, vol. 148, pp. 908-915, 2016.

[5] M. R. Ismail, "Evaluating the Dynamical Behavior and Stability of Pipes Conveying Fluid," 2011.

[6] M. J. Jweeg, et al., "Effects of Cracks on the Frequency Response of a Simply Supported Pipe conveying Fluid," International Journal of Mechanical \& Mechatronics Engineering, vol/issue: 17(5), pp. 109-113, 2017.

[7] Hadjami, et al., "Analytical Model of Cage Induction Machine Dedicated to the Study of the Inner Race Bearing Fault," International Journal of Electrical and Computer Engineering (IJECE), vol/issue: 8(1), pp. 458-471, 2018.

[8] A. Israr, "Vibration Analysis of Cracked Aluminum Plates," Ph. D. Thesis, Engineering Department of Mechanical Engineering, University of Glasgow, 2008.

[9] A. E. Suradkar and S. R. Suryawanshi, "Numerical Analysis of Fluid Flow Induce Vibration of Pipes-A Review," International Journal of modern Trends in Engineering and Research, vol/issue: 3(4), 2016.

[10] M. J. Jweeg and T. J. Ntayeesh, "Determination of Critical Buckling Velocities of Pipes Conveying Fluid Rested on Different Supports Conditions," International Journal of Computer Applications, vol/issue: 134(10), 2016.

[11] M. Al-Waily, et al., "Flow Velocity and Crack Angle Effect on Vibration and Flow Characterization for Pipe Induce Vibration," International Journal of Mechanical \& Mechatronics Engineering, vol/issue: 17(05), 2017.

[12] R. Veerapandi, et al., "Experimental Study and Analysis of Flow Induced Vibration in a pipeline," International Journal of Engineering Research and Technology, vol/issue: 3(5), 2014.

[13] Mediano V. B. and Garcia P. M. I., "Stability Analysis of a Clamped Pinned Pipeline Conveying Fluid," wseas transactions on systems, vol. 13, 2014.

[14] Sadeghioon A. M., et al., "SmartPipes: Smart wireless sensor networks for leak detection in water pipelines," J. Sensor and Actuator Network (JSAN), vol. 3, pp. 64-78, 2014.

[15] G. Rajita and N. Mandal, "Review on transit time ultrasonic flowmeter," Control, Instrumentation, Energy \& Communication (CIEC), 2016 2nd International Conference on. IEEE, 2016. 